\title{
A PROPRIEDADE INTELECTUAL E SEUS ASPECTOS NO ÂMBITO DO MERCOSUL
}

\author{
Helena Aranda Barrozo 1 \\ Marcia Ieshima 2
}

SUMARIO: 1. Introduço - 2. Rodada do Unugai - 3. O contendo do Acordo IRIP'S - Trade Related Aspets of Intellectual Property Rights - 3.1. Marcas - 3.1.1. Marcas colctivas - 3.1.2. Marcas de certiflcaca - 3.1.3. Marca notoriamente conhecida3.1.4. Esgotamento do dreito - 3.2. Patentes - 3.2.1. Direitos conferidos pela Patente - 3.3. Desenhos industriais - 3.4. Transferencia de tecnologia - 3.5. Protecäo de informaţa confidencial - 4. Os Direitos Hbridos - 5. O Acordo TRIPS no Brasil - 6. A Conconencia desteal - 7. A propriedade intelectual no Mercosul - 8. Conclusoes 9. Bibliogrdia.

SUMMARY: 1. Introduction-2. Round negotiations of Urigtay - 3. The content of TRPS pact-Irade Related Aspecis of Intellectual Property Rights - 3.1. Marks - 3.1.1. Coletive marks - 3.1.2. Certification Marks - 3.1.3. Well-known mark - 3.1.4. Law prostration - 3.2. Patents - 3.2.1. Patents right - 3.3. Industrial draw - 3.4. Transference of tecnology - 3.5. Protection of confidental information - 4. Hybrid laws - 5. The TRP's pact in Brazil - 6. The mfair compeition - 7. The intellectial property in Mercosul - 8. Conclusions - 9. Bibliography.

ÜBERSICHT: 1. Einfuhrung - 2. Unuguay-Runde - 3. Der Inhait des TRIPSVertrages (Trade Related Aspects of Intellectual Property Rights) - 3.1. Marken.

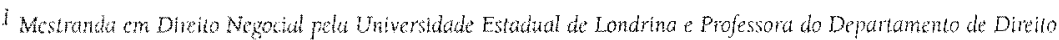
Privido da Linuersidate Estadual de Londrina.

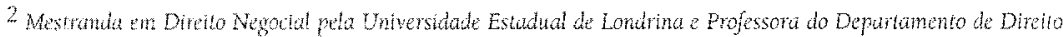
Privido da Universtade Estadial de Londrina.
} 
3.1.1.Kollektimarken - 3.1.2 Zertifikationsmarken - 3.1.3. Notorische Monke - 3.1.4. Erschopfung des Markenrechts - 3.2. Patente - 3.2.1. Vom patent verliehene Rechle 33. Geschmachmuster - 3.4. Ubertragung technischer Lizenzen - 3.5. Schutz anvertrater Geheimnisse - 4. Mischformen - 5. Der TRTPS - Vertrag in Brasilien 6. Der unlautere Wetbewerb - 7. Das geistige Eigentum im Mercosul - 8 . Shlussfolgenngen - 9. Bibliographie.

RESUMO: Sob os auspicios da Organizacão Mundial do Comércio e, retomando os compromissos assumidos quando das negociacoes da Rodada Uruguai do GATT, novas perspectivas se apresentaram em razāo do desequibibrio economico global, na década de 80. A preocupaça em proceder ajustes legais sobre alguns aspectos, ampliou a discussão para temas como: o comércio de serviços e a propriedade intelectual. A propriedade intelectual fez nascer um novo ordenamento com contornos prophtos de um diretio de cunho intemacional de carater eminentemente hibrido, e como tal, deve ser protegido. O presente trabalho aborda, inicialmente a conceituação e legislaçoses internacionais e nacionais aplicaveis, para em seguida tecer algumas consideraçes acerca da propriedade intelectual, em especial, no Mercosul.

ABSTRACT: Under the World Trade Organization's ruling and taking up the agenda set when of the GATT's Uruguay Round negotiations, new perspectives have been presented due to the global cconomic imbalance in the 80s. The concern about carring out legal adjustments has broadened the discussion over matters such as the trade of services and the intellectual property. The latter gave rise to a new order with very particular characteristics of the Intemacional Law, with a hybrid nature and as such, should be protected. The present study, initially, deals with the applicable national and international concepts and laws following a few considerations on the intellectual property, in special, within Mercosul.

ZUSAMMENFASSUNG: Unter der Herrschat der Welhandelsorganisation und durch den Ruckgriff auf die anlasslich der Uruguay - Runde eingegangenen Verpflichtungen haben sich in den 80 er 
Jahren aufgrund des weltweiten wirtschaftlichen Ungleichgewichts neue Perspektiven ergeben. Die Bemühungen um eine rechtliche Anpassung hat die Diskussion um Themen erweitert wie: der Handel mit Dienstleistungen und das geistige Eigentum. Das geistige Eigentum hat eine neue Ordnung cntstehen lassen, welche die Eigenarten des internationalen Rechts aufweist, in besonderem Mass Mischformen enthalt und deshalb des Schutzes bedarf. Die vorliegende Arbeit erörtertert zunächst die Begriffe und die Gesetzgebung im nationalen und internationalen Recht; hieran knupfen sich einige Überlegungen zum geistigen Eigentum an, insbesondere im Mercosul.

PALAVRAS CHAVE: Propriedade Intelectual. TRIPs. GATT/OMC. Direitos hỉbridos. Mercosul. Internalizaçâo de normas intemacionais. Concorrencia desteal.

KEY-WORDS: Intellectual property. TRIPS. GATTNTO. Hybrid laws. Mercosul. Internalization of internacional regulations. Unfair competition.

SCHLUSSELWÖRTER: Geistiges Figentum. TRIPS. GATNWTO. rechtliche Mischformen. Mercosul. Transformation Internationaler Normen in nationales Recht. Unlauterer Wettbewerb.

\section{Introdução}

A definição de Propriedade Intelectual é dada pela Organização Mundial da Propriedade Intelectual (OMPI) como a soma dos direitos relativos as obras literärias, artisticas e cientificas, as interpretą̧oes dos artistas, intérpretes $e$ as execuçôes dos artistas executantes, aos fonogramas e às emissôes de radiodifusão, as invençōes em todos os dominios da atividade humana, às descobertas cientificas, aos modelos e desenhos industriais, as marcas industriais, comerciais e de serviços, bem como às firmas comerciais e denominações comerciais, à proteça contra a concorrencia desteal e todos os outros direitos inerentes à atividade intelectual nos dominios industrial, cientifico, literário e artistico. 
Inicialmente, necessário se faz ressaltar a dualidade de sistemas existente entre direito do autor e direito do inventor, pelo fato de que ambos säo considerados modos de proteçăo e a partir dai o Estado vem adotar um sistema duplo de proteção: direitos de autor e direitos conexos, mais os decorrentes da concessão de patentes de invenção, marcas e correlatos.

A análise vem merecer consideraçoes das teorias desenvolvidas tanto na eslera do direito público como no direito privado.

Para os publicistas, e em especial PAUL LABAND², o estudo desses direitos tem por base três instituiçôes altamente importantes: monopólio, delito e reflexo. Nesse sentido, o direito do autor constitui-se num monopólio pois, implica na restrição à liberdade geral do comércio, já que a colocação em valor comercial do trabatho intelectual é reservada exclusivamente ao autor e aqueles a quem o autor confere seus direitos, conseqüentemente a violação dessa regra ensejaria aplicação de pena, indenização por perdas e danos ou multa.

A partir do instante em que haja uma reprodução ou uma contrafação estaria caracterizado o delito. Quanto ao reflexo, implica na consagração dos direitos de liberdade protegidos no âmbito constitucional dos paises inclinados a consagrar os direitos de liberdade. Esses direitos seriam pura e simplesmente reflexos do direito estatal, ou seja, do direito objetivo.

$\mathrm{Na}$ esfera do direito privado vamos encontrar teorias que colocam os direitos de autores e inventores dentre as categorias convencionais do direito privado. Por outro lado, autores defendem a colocação desses direitos numa categoria especifica.

Na categoria tradicional do direito privado temos a clássica divisão dos cireitos em a) pessoais, ligados à pessoa do titular, b) reais, referentes aos bens materiais e c) obrigacionais, na sujeição do sujeito passivo ante ao direito do sujeito ativo. Contudo, a última classificação não se aplica ao campo dos direitos intelectuais.

Assim sendo, as principais teorias do direito privado acabam por

3 Trute du droit public de lempire alemand. apud. Marstela Basso. O direito intermacional da propriedade intelectual. Forto Alegre.Liwata de Advogado, 2000, p. 28-32. 
abranger o direito pessoal e o direito real, sendo que a maioria dos autores consideram direitos de autores $e$ inventores legítimos direitos de propriedade. Então, se a propriedade pertence ao autor (idealizador), natural que possa utilizar e dispor desse direito. Indagando acerca da natureza juridica da propriedade intelectual, chega-se a um posicionamento unânime de tratar-se de um direito real.

Importante destacar que os direitos oriundos da produção intelectual possuem caráter imaterial, de características intemacional e cosmopolita. EDMOND PICARD4, mesmo antes da Convenção de Berna de 1886 veio colocar: a produção do espirito, objeto do direito intelectual, destina-se naturalmente a expandir-se a todos os lugares onde vat a civilizaçào. Ela é divisivel ao infinito, mais permanece sempre una. O autor de um livro, o inventor de um processo industrial, aquele que produziu uma obra musical ou uma obra suscetivet de ser divulgada por não importa qual arte ou desenho, certamente não trabalhou unicamente para seu pequeno mundo, no qual ele vive, nem mesmo para a naçäo à qual ele pertence. Seu desejo, sua esperança, $e$ de ver seu trabalho expandir: Sua intensidade não se perde, mas, ao se expandir, adquire um vigor novo. O que, para uma coisa material, implicaria em impossibilidade ou destrutção, se torna, para uma coisa intelectual, uma oportunidade de força e de celebridade.

A proteção da Propriedade Intelectual tem suas origens na Convenção da Uniāo de Paris para a Proteção da Propriedade Industrial de 1883. Referida Convenção não propugnou pela uniformização das leis nacionais, nem tampouco veio condicionar um tratamento nacional recíproco.

Na verdade, buscou estabelecer ampla liberdade legislativa para cada pais, respeitando-se a paridade. Pois, até bem pouco tempo, no contexto internacional não se dispunha de um conjunto de normas dotadas de sanção que, excepcionalmente, pudesse ser aplicado contra um Estado que se negasse a cumprir em seu território as nomas internacionais de proteção à propriedade intelectual.

A partir de 1995, com o advento da Organização Mundial do

\footnotetext{
4 Embryologie juidique, nouvelle classification des droits, in Journal de Drot Prive ta Chunet, $1 . \mathrm{x}, 1883$, p.566. apud. op.cit., is. 19-20.
} 
Comércio, referida proteção ganhou uma nova dimensão com a criação de instrumentos de sanção internacional nas relaçoes entre os Estados, que veio a se eletivar com a assinatura do Acordo TRIP'S (Trade Related Aspects of Intellectud Property Rights), com os mesmos objetivos estabelecidos naquela Convenção.

\section{Rodada Uruguai}

Com a Rodada do Uruguai (1986), em Punta del Este, considerado o maior evento em termos de volume de comércio do planeta, cuja realização contou com a participação da maioria dos países do mundo; iniciou-se a oitava Rodada de Negociaçóes Comerciais Multilaterais patrocinadas pelo GATT,

Três fatores basilares foram decisivos:

a) os desequilibrios globais do sistema economico durante a década de 80;

b) as questões não solucionadas na Rodada de Tóquio, ou seja, os diversos vazios legais do sistema do GATT, que permitem transgressoes a seu espirito, ainda que não à suas letras, segundo palavras de Aberto Isgut, dentre os quais podemse citar o exemplo das salvaguardas, que tenderam a agravar-se durante os anos 80 ;

c) a introduçāo de novos temas, como o comércio de serviços, a propriedade intelectual, as medidas de investimento relacionadas ao comércio e o Conflito Norte-Sul'.

Levando em consideração esses três elementos, bem como detectados os pontos sensiveis da Instituição, na Rodada do Uruguai foram instituidos 15 Grupos Negociadores. E dentre eles, o grupo negociador $n^{\circ} 11$ - que trata dos Direitos de Propriedade Intelectual relacionados ao Comércio, inclusive - Comércio de Bens Contrafeitos; cujas negociaçóes acerca dos aspectos da propriedade intelectual, buscavam a proteção desta no âmbito da OMC.

Ditas negociaçoes objetivavam atender os interesses dos paises industrializados, assegurar proteção mais rígida para os direitos dos

5 SIVA, Robero Luiz. Direito economico internacional e direito comunitário. Belo Horizonte:Del Rey, 1995, p.87. 88. 
produtores de tecnologia; e ao mesmo tempo proteger os paises em desenvolvimento e mais industrializados na busca de tecnologias para maior incremento de suas indústrias.

Assim, considerada a maior e mais longa negociaçăo na história do comércio mundial, com a duração de sete anos e meio e participação de 125 países, a Rodada Uruguai, embora parecesse fadada ao fracasso, provocou a maior reforma no sistema comercial mundial desde a criação do GATT pois, este não tinha poder para solucionar as controvérsias comerciais ou impedir que seus membros descumprissem suas regras.

Ao final da Rodada do Uruguai foi assinado o acordo ADIPIC - Acordo sobre Aspectos Relacionados ao Comércio dos Direitos à Propriedade Intelectual, Inclusive o Comércio de Bens Contrafeitos, visando a proteçāo desse direito, recomendando um periodo de transição para internalização de suas medidas.

No âmbito do Mercosul houve a aprovação do Protocolo de Harmonização e Procedimento sobre Propriedade Intelectual, assinado em agosto de 1.995 - Decisão $8 / 95$ do CMC - submetido à consideração do Congresso Nacional pela Mensagem $n^{\circ} 681$, de 1996. No entanto, a Mensagem MSC 1.872, aprovada em 18/05/2000, veio suspender a tramitação do Decreto Legislativo $n^{\circ} 475 / 97$ - contendo proposta para incorporação do referido Acordo.

Após a devida ratificação dos Estados-Partes, referido Protocolo cleverá integrar o Tratado de Assunção.

\section{O conteúdo do Acordo TRIP'S - Trade Related Aspects of Intellectual Property Rights}

Considerada na atualidade como principal instrumento internacional sobre Propriedade Intelectual, surgiu do Acordo de Marraquech (Anexo 1C que instituiu a Organização Mundial do Comércio).

O Acordo TRIP's preserva, com algumas ressalvas, princípios já existentes para regulamentação do comércio internacional, constantes do Acordo primitivo - GATT de 1947 - a saber: 
a) principio do tratamento nacional, que consiste na probição de tratamento discricionário a membros não nacionais;

b) princípio da naçào mais favorecida, estendendo de forma incondicional a concessão automática de vantagem, favor, privilégio ou imunidade concedido por um membro a nacional de outro membro, aos demais membros da OMC. Assim, será dado tratamento igualitário a todos os membros da organização, mesmo aos que não tenham participado das negociaçōes;

c) possibilidade de excecoes, permite-se aos Estados que adotem medidas necessárias para proteger a saude e nutriça públicas para promover o interesse publico em setores de importancia vital para seu desenvolvimento sócio-econômico e tecnologico, desde que estas medidas sejam compativeis com o disposto neste Acordo(...) e para evitar o abuso de direitos de propriedade intelectual por seus titulares ou para evitar o recurso a praticas que limitem de maneira injustificáel o comécio ou que afetem adversamente a transferència internacional de tecnologia (art. $8^{\circ}$, parágrafos $1^{\circ}$ e $2^{\circ}$ ).

Convém ressaltar que no seu âmbito ainda prevalece uma série de acordos e tratados, dentre os quais o Acordo de Madri, de 1891 - registro internacional de marcas; no mesmo ano o Acordo de Indicaçóes de Procedência ainda em vigor no Brasil na sua revisão de 1925; o Acordo de Haia de Patentes de Desenho e Modelo Industrial; o Acordo de Nice classificação de marcas; o Acordo de Estrasburgo - classificação de patentes; o Patent Cooperation Treaty de Washington de 1970; O Tratado de Viena Signos Tipográficos; Tratado de Praga para Depósitos de Microorganismos.

Além da Convenção existem tratados de conteúdo peculiar, como o Registro de Descobertas Cientílicas; a Convenção de 1961 sobre Proteção de Cultivares, ou Variedades de Plantas (UPOV); bem como o Tratado de Washington sobre Topografias de Circuitos Integrados, ainda não vigente.

Para o Professor LUIZ OTAVIO PIMENTEL, o Acordo TRIP'S - dada a sua caracteristica de globalidade externa e portanto vinculado de foma 
integral à Organização Mundial do Comércio, - estabelece a estrutura jurídica a ser observada pelos seus membros. Isso significa que - no âmbito interno, ou como denominou, globalidade interna - não podem ser elaboradas reservas a qualquer dos dispositivos daquele sem o consentimento dos demais membros.

Entende ainda que, o baixo nível jurídico do Acordo TRIP'S se deve a ausência de rigor na formulação dos conceitos técnico-jurídicos, e que sua manutenção no tempo se fez em razão da incorporação em seu seio de convenção internacionais anteriores. Caso contrário, não teria sobrevivido.

Resta-nos então, o problema doutrinário do Acordo TRIP'S: seria ele auto-executável ou não? LUIZ OTáVIO PIMENTEL na mesma esteira de GÓMEZ SEGADE entende que o acordo em seu conjunto não é auto-executivo, porque as obrigações se impõem diretamente aos membros, quer dizer aos Estados que o subscreveram. A circunstância de que os direitos de propriedade intelectual sejam reconhecidos pelos TRIPS como direitos privados não determina considerálos auto-executivos nas relaçöes onde um dos sujeitos é uma pessoa de direito privado'.

\subsection{Marcas}

De modo geral, define-se a Marca como sendo qualquer sinal distintivo que possa identificar um produto ou serviço. Ao comerciante detentor de seu registro representa a possibilidade da formação de sua clientela. Para o consumidor, constitui-se num referencial para a compra de um determinado bem a partir da consideração de alguns fatores, como procedência, qualidade e desempenho.

Sob o ponto de vista econômico, a Marca desempenha dupla função: no campo público, constitui-se num eficiente mecanismo de defesa do consumidor, ante a possibilidade de confusão no momento da escolha do

\footnotetext{
6 Propriedade intelectual. In: BARRAL,WELBER (Org.) O Brasil e a OMC: os interesses brasileiros e as futuras negociações multilaterais. Florianópolis: Editora Diploma Legal, 2000, p. 71.

7 Ibid, p. 72 .
} 
produto; na esfera privada, possibilita ao seu titular o enfrentamento da concorrência desleal.

Para MARISTELA BASSO', o art. 15.1 do TRIPS vem referir-se à matéria objeto de proteção no campo das marcas:

Qualquer sinal, ou combinaçäo de sinais, capaz de distinguir bens e serviços de um empreendimento daqueles de outro empreendimento, poderá constituir uma marca. Estes sinais, em particular palavras, inclusive nomes próprios, letras, numerais, elementos figurativos e combinação de cores, bem como qualquer combinação desses sinais, seräo registrảveis como marcas. Quando os sinais não forem intrinsicamente capazes de distinguir os bens e serviços pertinentes, os Membros poderäo condicionar a possibilidade do registro ao carater distintivo que tenham adquirido pelo seu uso. Os Membros poderăo exigir, como condiçáo para o registro, que os sinais sejam visualmente perceptiveis.

Da análise do Acordo TRIPS verifica-se a ampliação da proteção dada pela Convenção de Paris, ao incluir os "serviços" no rol da proteçäo e consequente compromisso dos Estados-Partes no registro das marcas de servicos.

No art. 16.1 do Acordo encontram-se os denominados DIREITOS EXCIUSIVOS:

O titular de marca registrada gozara de direito exclusivo de impedir que terceiros, sem seu consentimento, utilizem em operaçöes comerciais sinais idênticos ou similares para bens ou serviços que sejam identicos ou similares aqueles para os quais a marca está registrada, quando esse uso possa resultar em confusão. No caso de utilização de um sinal idèntico para bens e serviços identicos presumir-se-â uma possibilidade de confusão. Os direitos descritos acima não prejudicaräo quaisquer direitos previos existentes, nem afetarão a possibilidade dos Membros reconhecerem direitos baseados no uso.

\footnotetext{
8 BASSO, Marisela, O direito internacional da propriedade intelectual. Poto Alegrelivraria do Advogado, 2000 [. 209 .
} 


\subsubsection{Marcas coletivas}

Historicamente, as primeiras referências às marcas coletivas aparecem na idade média, entre os romanos. Segundo Ladas Corporaçós de Artes e oficios possuiam marca coletiva para todos os seus membros e estes tinham o direito assegurado de as adotar ${ }^{10}$.

Na era moderna, o desenvolvimento industrial propicia o surgimento de associações, uniōes e federaçoes de classes, produtores ou industriais que, objetivando garantir a qualidade de seus produtos, por meio da divulgação dos métodos empregados na fabricaçăo dos mesmos e indicação de procedência, vêm propugnar pela criação da marca coletiva.

Dessa forma, conceituá-se a marca coletiva como a marca de toda uma comunidade, de um agrupamento de pessoas juridicas de natureza privada ou pública, destinada a assinalar e distinguir os produtos efou mercadorias oriundas de uma cidade, região, como se fora o selo de garantia, autenticidade, excelência e qualidade. A marca coletiva, embora pertença a toda comunidade, em realidade, visa aos interesses dos produtores ou industriais que, não obstante a utilizem de per si, tem conjunto a sua chancela de comunidade. A titular desses direitos e na salvaguarda daqueles outros, dos seus integrantes, detém para si näo só o controle da qualidade como, também, da defesa contra os possiveis infratores"

Como se vê, a importãncia da adoçăo da marca coletiva - identilicando produto ou serviço como originários de um certo país, região ou localidade - tende a lacilitar em muito a circulação dos referidos bens.

Assim sendo, o seu uso é mais do que justificável e necessário dentre os países economicamente integrados, dando-lhes sustentabilidade de mercados para seus produtos por meio da garantia sobre a procedência e qualidade por eles atestada.

\footnotetext{
9 Ibid, p. 213.

10 SOARES, Jose Carios Tinow. Lei de Patentes, marcas e direitos conexos - Le1 9.270 - 14/05/1996. Editorat Revisia dos Tribunais, $1997, \mathrm{p}, 239$.

11 SOARS Jose Cartos Tnoco. Estudo e Regime tas Marcas Coletivas e de Certificacá e Demominacoes de Origem - Conventencia de sua Adoço. Revista dos Tribunais, São Panlo, n. 562, p. 09-27, ago 1982.
} 


\subsubsection{Marcas de certificação}

A Marca é elemento caracterizador de um produto ou serviço, de forma a torná-lo distinto de outro idêntico, semelhante ou afim.

Considera-se Marca de Certificação sinais não só distintivos do produto ou e de serviço, mas os sinais que possam atestar sua produção em conformidade com normas e especificaçōes técnicas, dando-lhe caráter de confiabilidade pela qualidade, natureza, material e metodologia empregados na sua elaboraçào.

A principal finalidade da marca de certificação é dar ao consumidor a garantia de que o produto objeto de consumo foi fabricado dentro da mais rigorosa técnica, e da altíssima qualidade dos serviços.

Muitos paises se utilizam da marca de certificaçäo para distinguir seus produtos e serviços dos similares existentes no mercado, assegurando, ao mesmo tempo, as condiçoes de qualidade de sua produção. Alguns deles adotam a marca de certificação como instrumento a ser utilizado pelas pessoas jurídicas, que permite estabelecer uma conexão de seus produtos ou serviços, servindo para indicar sua procedencia, qualidade entre outros.

No atual estágio do processo de globalização econômica, evidencia-se uma crescente preocupação dos paises em relação às Marcas de Certificação com o proposito de se conquistar novos e fiéis mercados.

Dessa forma, a certificação deverá ser concedida à marca que tenha o seu reconhecimento pelos órgãos de pesquisa ou entidade, que possam afirmar a preferência do consumidor pelo produto ou serviço, levando-se em conta os padröes de qualidade resultantes da tecnologia empregada na sua elaboração. Consequentemente, o detentor dessa marca, além de distinguir seus produtos ou serviços dos similares no mercado, terá asseguradas, ao mesmo tempo, as condiçóes de qualidade de sua produção.

Do exposto, resta evidente o entendimento da doutrina (especificamente da doutrina estrangeira), de que a marca de certificação representa uma outorga de direito, de prêmio ou equivalente e como tal não deveria ser submetida a pedido de registro, mas sim à consagração ${ }^{12}$.

Para tanto, são indispensáveis, para aquisição desse direito, as caracteristicas do produto, em conformidade com a especificação das chamadas medidas de controle adotadas pelo interessado na certificação. 
Há, ainda, um outro entendimento, esse no sentido de que a certificaça seja concedida à marca que tenha o seu reconhecimento pelos órgãos de pesquisa ou outra entidade que possam confimar a preferência do consumidor pelo produto ou serviço, levando-se em conta os padröes de qualidade adotados na sua elaboração, de sorte a angariar total preferencia da clientela.

Ocorrendo a padtonização legislativa entre os Estados-Membros do bloco, parece não estar muito distante a possibilidade de criacăo da Marca MERCOSUL, como indicaçăo de procedencia e certilicação de qualidade, a exemplo do que já ocorre na Uniăo Européia.

\subsubsection{Marca notoriamente conhecida}

$O$ art. 6.-bis (I) da União de Paris vem conferir proteção especial à marca notoriamente conhecida, estabelecendo que os paises comprometem-se a recusar ou invalidar o registro de marca de fábrica ou de comércio que constitua reprodução, imitação ou tradução, suscetivel de estabelecer confusão, de uma marca que a autoridade do pais do registro ou do uso considere que nele é notoriamente conhecida.

Observa-se, então, limitação ao uso da marca notoriamente conhecida no território do país de registro, e não em qualquer parte do mundo.

O referido dispositivo não faz menção aos serviços. Já o Acordo TRIPS vem explicitar melhor o assunto em seu art. 16.2, abaixo transcrito:

o disposto do Artigo 6 bis da Convençäo de Paris (1967) aplicar-se-ä. mutatis mutandis, a serviços. Ao determinar se uma marca notoriamente conhecida, os Membros levarão em consideração o conhecimento da marca no setor pertinente do pablico, inclusive o conhecimento que tenha sido obtido naquele Membro; como resultado de promoção da marca.

No que tange aos serviços, há que se considerar os que "não sejam similares àqueles para os quais uma marca esteja registrada, desde que o uso dessa marca, em relação àqueles bens e serviços, possa indicar uma conexão entre aqueles bens e servicos e o titular da marca registrada e desde que seja

12 SOARE5, Jose Catos Tinoto. Lei de Patentes, marcas e direitos conexos - Lei 9.279-14/05/1996. Editom Revista dos Tribunais, 1997, p. 248. 
provavel que esse uso prejudique os interesses do titular da marca registrada"

\subsubsection{Esgotamento do direito ${ }^{14}$}

O registro de uma marca não poderá impedir a livre circulação dos produtos no mercado. Os Estados-Partes se comprometem a prever, em suas respectivas legislaçóes, medidas que estabeleçam o esgotamento do direito conferido por esse registro.

Maristela Basso ${ }^{15}$, aborda o tema dentro do principio do esgotamento internacional dos direitos ou exaustäo de direitos, onde o direito de exclusão comercial do titular do direito de propriedade intelectual se esgota (exaure, termina) no monento em que introduz o produto patenteado no coménio ou consente que isso seja feito por terceiro. Ao realizar a primeira comercializaçäo; 0 direito do titular se esgota de tal forma que os produtos introduzidos no comércio poderão ser objeto de atos, ulteriores e sucessivos, de comercialização, näo mais poderá probir ou restringir que terceiros comercializem, ulteriormente, produtos com a tal marca, o que denomina "vendas paralelas" ou "distribuiçoes paralelas".

Para Raquel Flanzbaum, o local onde se tenha colocado o produto no comércio pela primeira vez não interessa à disposiçâo legal, pois o que importa é que o direito de propriedade industrial não impeça a livre circulação dos produtos. Como se trata de uma norma de caráter regional logicamente tende a que, dentro do território do Mercosul, o registro nacional de uma marca não venha trazer obstaculos a live circulaçăo dos produtos que a utilizem licilamente. Se bem que, nem Argentina e nem o Brasil tratem especificamente do tema em suas legislacoos, deve-se entender que o Brasil se

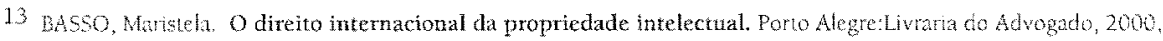
1). $21+$

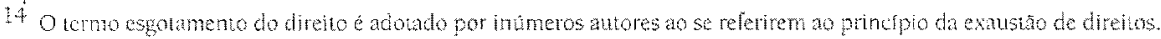
Dente esses auores tem-se Luz Otavio Pinentel, Maristela Basso e Raguel Fanzam. Esta ultima, em palesta

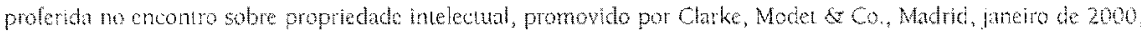
p.5.17, va mais atem, defendendo que esgotamento do direto das mas parte de uma conepero mas restrita

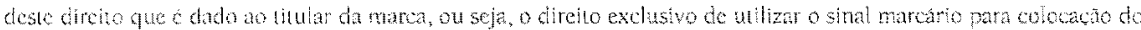

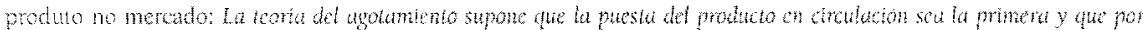

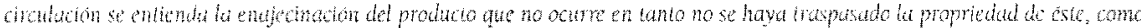

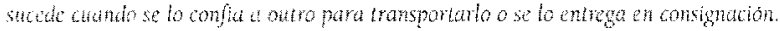

15 op ant, 200, p. 181-183. 
inclina mais pelo esgotamento regional e a Argentina pelo esgotamento internacional. Ja o Paraguai introduziu essa figura em sua legislaça adotando o sistema internacional, da mesma forma que o Uruguai. Quanto do Chile, ainda näo existe qualquer legislação. ${ }^{16}$

Delende ainda que, o marco da integração regional e as fronteiras nacionais fazem com que, necessariamente, o esgotamento do direito deva ser observado sob três possibilidades territoriais: esgotamento nacional, regional ou internacional, principalmente em razão do Mercosul, pois o Protocolo preve que o registro de uma marca não poderá impedir a livre circulação dos produtos marcados introduzidos legitimamente no comércio pelo seu titular ou com a autorização do mesmo.

\subsection{Patentes}

Denomina-se sistema de patentes o conjunto de regras que se destina à proteção das invenções direcionadas à indústria.

A Patente é definida como uma outorga do Estado a uma pessoa da exclusividade na exploraçăo do objeto resultante de uma invenção, de um modelo de utilidade, por um determinado tempo em todo território nacional.

A adoçăo de um sistema de patentes justifica-se não só pelo aspecto de direito, mas também pelo da técnica, da economia e do desenvolvimento dos paises.

Juridicamente, há que se proteger a pessoa do inventor pelo direito da propriedade originário do bem imaterial, resultante de sua invenção. Muito embora a importância da invenção esteja diretamente ligada à sua divulgação - sem o que o inventor deixaria de ganhar notoriedade, o direito de propriedade ficaria prejudicado em sua essência caso nāo se concedesse ao inventor o beneficio do privilégio.

A defesa da propriedade imaterial já constava da Ordem de Patentes Venezianas, elaborada na cidade de Veneza em 1474. Referencial histórico,

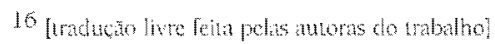


com repercussões nos sistemas vigentes, é a Convencão da Uniäo de Paris para Protecăo da Propriedade Industrial que, progressivamente, viabilizou a globalização da matéria.

No campo da técnica, a patente se revela como instrumento altamente estimulante para o emprego de novos métodos que venham ao encontro das expectativas da sociedade, acelerando o desenvolvimento. Por isso, justificase a adocăo do sistema por todas as naçóes do mundo, näo importando seu grau de desenvolvimento.

No contexto do Acordo TRIPS, constata-se certo detalhamento quanto às regras das patentes, em razão das dificuldades ocorridas no momento das negociaçes da Rodada Uiuguai, ante as imposiçoes colocadas pelos paises mais desenvolvidos. A matéria vem regulada na Secăo 5 da Parte 11 - arts. 27 a 34, alem das disposiçoes das Partes VI e VII.

No artigo 27 - primeira parte, encontram-se alinhados os requisitos minimos para concessão de patente, quais sejam:

qualquer invença, de produto ou de processo, em todos os setores tecnologicos, setá patenteavel desde que seja nova, envolva um passo inventivo e seja passivel de aplicacao industrial

Assim não sera passivel de patenteabilidade o que estiver contido na esfera do óbvio e que não possa servir à producăo industrial.

A $2^{a}$. Parte do mesmo artigo vem estabelecer a inclusäo no sistema da Organizacăo Mundial do Comércio da cláusula de náo discriminaça, permilindo a concessão de patente a todos os tipos de invençăo, näo importando a que setor industrial ou tecnologico pertençam, e se a producáo é local ou importada. Exceça à regra consta do parágrafo 4 do art. 65 , do parágralo 8 do art. 70 e do parágrafo 3 do art. 27 (periodo de transitotiedade para os patses Membros em fase de desenvolvimento, e exceçós de patenteabiliciade).

No que concerne às excecóes à patentabilidade, é facultado aos Membros desconsiderarem a protecăo da patente quando esta atentar contra a moral e a ordem pública do seu territorio, ou ainda, para proteger a vida ou saúde humana, animal ou vegetal, como também para evitar danos ao meio ambiente. 
Poderão os Membros considerar como não patenteáveis:

a) métodos diagnósticos, terapêtuticos e cinirgicos para tratamento de seres humanos ou de animais;

b) plantas e animais, exceto microorganismos e processos essencialmente biologicos para a produçäo de plantas ou animais, excetuando-se os processos não biológicos e microbiológicos. Não obstante os membros concederäo proteçăo a variedades vegetais, seja por meio de patentes, seja por meio de um sistema sui generis eficaz, seja por uma combinação de ambos. O disposto neste subparágrafo será revisto quatro anos após a entrada em vigor do Acordo Constitutivo da OMC.

Säo igualmente mencionadas no art. $27-a$ as exceçöes relativas aos métodos médicos utilizados na formulação de diagnósticos, e que são de somenos importância para a esfera econômica e comercial,; na letra b, encontram-se as exclusöes que muita polêmica têm causado entre os paises, por ser de real interesse à Comunidade Européia. Tratam- das variedades de plantas e raças animais, e os processos biológicos para a produção de plantas e animais.

Os microorganismos e os processos microbiológicos e não biológicos de reprodução são patenteáveis, inclusive os transgênicos (resultantes da ação direta do homem sobre seu estado natural).

\section{2.l. Direitos Conferidos Pela Patente}

O art.28.1 do TRIPS estabelece que:

uma patente conferira a seu titular os seguintes dreitos exclusivos:

a) quando o objeto da patente for um produto, o de evitar que terceiros sem seu consentimento produzam, usem, coloquem a venda, vendam, ou importem com esses propósitos aquetes bens;

b) quando o objeto da patente for um processo, o de evitar que terceiros sem seu consentimento usem o processo e usem, coloque a venda, vendam, ou importem com esses propósitos pelo menos o produto obtido diretamente por aquele processo.

Os titulares de patente năo estão impedidos de ceder ou transferir seus direitos, quer por via de sucessão ou celebração de contrato específico para sua exploração. 
O Acordo TRIPS distingue patentes de produto das patentes de processo. As primeiras vêtm proibir - a terceiros năo autorizados - a fabricação, uso, oferta para venda, venda ou importação com esses fins do objeto da patente. As segundas, proíbem a utilização do processo, para os mesmos fins, o que leva a concluir que a proteção dada à patente do processo não se desvincula do produto resultante do processo já patenteado.

art. 29.1.1 parte consagra o principio da revelaçâo ou divulgação da invenção, como condição para solicitação de patente. Veja-se na sequência:

Os Membros exigirão que um requerente de uma patente divulgue a invença de modo suficientemente claro e completo para permitir que um técnico habilitado possa realizá-lat?.

Tal disposição não se refere às invenções biológicas quc, pela própria natureza, não podem ser descrítas. Os Estados-Partes deverão fixar as regras, não só quanto à forma de descrição dessas invençōes, como também do depósito dos materiais necessários à descrição, indicando as possibilidades a terceiros para acessát-las.

O conjunto dessas disposições permite concluir que a patente se refere a um tipo especial de propriedade privada sobre bem imaterial, para proteger juridicamente a tecnologia, concedida após o exame do cumprimento de certos requisitos pela autoridade administrativa, tendo carater temporário e real's.

Quanto à caducidade das patentes, o Acordo remete aos EstadosPartes a incumbência de analisar as causas substantivas ou processuais de nulidade ou caducidade da patente, de acordo com as disposiçōes do Art. 32 (possibilidade de interposição de recurso judicial contra qualquer decisão de anular ou caducar uma patente).

Consoante $o$ art.33 do TRIPS, a proteção de uma patente dar-se-á por um prazo de 20 anos, contados a partir da data do depósito.

17 BASSO, Marstela O direito internacional da propriedade intelectual. Pono Alegre:Lwara do Adrogado, 2000, p. 234.

18 FMENTEL, Luiz Oavio. Direito Industrial - As funçoes do Direito de Patentes. Pono Alegre:Sinese, 1999, p. 218. 


\subsection{Desenhos industriais}

Num conceito genérico, o desenho industrial representa a configuração ornamental de um objeto que possa ser reproduzido em escala industrial.

A expressão design envolve conceitos relativos à forma plástica, linhas e cores de um objeto bidimensional ou tridimensional. No contexto intemacional, as expressöes desenho industrial e modeto industrial estão contidas no conceito de design ${ }^{19}$.

No direito comparado, verifica-se que a proteção do desenho industrial se dá pela adoção de sistemas especificos entre a maior parte dos países. Assim sendo, alguns ordenamentos baseiam-se nos procedimentos de registros; outros, vêm exigir a observância de determinados requisitos, tais como novidade, originalidade, aspecto estético ou caráter distintivo.

Apesar das diferenças de tratamento, fica evidente uma característica comum à maior parte das legislaçōes, quando admitem uma proteção coexistente ou cumulativa ${ }^{20}$. Num primeiro instante é dado ao criador do desenho industrial a faculdade de optar sob qual regime ficará protegido. Em seguida, dar-se- a a protecão concorrente, cumulativa, entre os regimes de proteça dos desenhos industriais e dos direitos de autor, ou dos desenhos industriais e dos direitos de propriedade industrial.

Em seu art. 25.1, estabelece para os Estados-Partes a obrigatoriedade da proteção dos desenhos industriais quando atenderem aos requisitos da novidade e originalidade. Contudo, näo traz a devida interpretação para esses critérios, de forma a distinguir o que realmente seja novo e original, deixando para que os Estados-Partes o façam em suas legislações.

Os direitos sobre desenhos industriais estão albergados no artigo 26.1 do Acordo, confome se segue:

o titular de um desenho industrial protegido terá o direito de impedir terceiros, sem sua autorizaçäo, de fazer, vender ou importar antigos que ostuntem ou incorporem um desenho que constitua uma cópia, ou seja

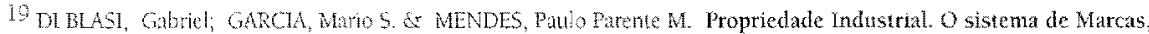
Patentes e Desenhos Industrixis Anatisados a partir da Lei 9.279 , de 14 de maio de 1996. Forense, $2000,0.180$.

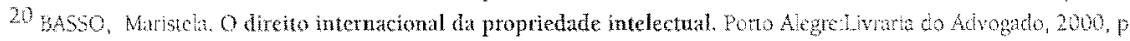
24.
} 
substancialmente uma copia, do desenho protegido, quando esses atos sejam realizados com fins comerciais.

Observe-se que ao titular do registro do desenho industrial é dado o "direito de impedir", e năo um direito de exclusividade, como aquele conlerido aos direitos de autor, e à titularidade de marcas e patentes. Fato esse que nào impede ao Estado-Parte estender o campo da proteção ao cumular o direito de impedir ao direito de produzir, usar, vender etc.

Admite-se a interposição de exceçoes à proteção dispeñada aos desenhos industriais quando; a) não forem injustificáveis em relação à proteça dada; b) quando disserem respeito aos atos estritamente comerciais.

Considerando-se as divergências no tratamento da questão, o Acordo TRIPS veio estabelecer padrões mínimos de uniformização para proteção dos desenhos industriais.

\subsection{Transferência de Tecnologia}

O know how trata-se de um bem imaterial de natureza distinta de outros bens imateriais como a criação intelectual, quer sob o prisma da estética (Direito Autoral), ou da utilidade/funcionalidade (Direito de Propriedade Industrial). Refere-se ao conhecimento ou técnica de cunho secreto, que se desenvolve na realização de uma atividade, com objetivo eminentemente utilitário.

Tendo em vista a necessidade de manutenção do sigilo, o know how é protegivel na concorrência desleal, no intuito de se preservar o interesse de seu titular, bem como o curso natural e honesto dos negócios. Tanto assim, que sua violação configuramse como delito contra o sistema da propriedade intelectual.

No âmbito do Direito de Propriedade Industrial, sua proteção configura-se in concreto desde que consubstanciado nos elementos materiais desse direito: patentes, desenhos, marcas e outros sinais,

Quanto ao Direito Autoral, desde que contido no campo cientifico. literário ou artístico, preservando o seu caráter de segredo.

Atualmente, por força do processo mundial de integraçöes econômicas, multiplicam-se os meios que possibilitam trocas de tecnologias 
através de tratados e contratos. Destaque-se que os tratados envolvem a transferência de tecnologia entre Estados; enquanto que os contratos são celebrados entre pessoa lisica ou juridica e o Estado, ou empresa interessada.

Os tratados ou acordos (bi ou multilaterais) regem-se pelas disposiçoes estabelecidas no momento das negociaçóes. Confomes ao direito internacional público, as regras estabelecidas baseiam-se nos costumes, sendo que outras decorrem de resoluçoes internacionais, não se prescindindo do caráter de segredo.

Já os contratos, denominados de transferência ou de comunicação de know how, regem-se por dispositivos especiais do poder público. São os contratos de natureza híbrida (contratos-padrões ou contratos-tipos), e poderão ter por objeto uma cessäo, prestaçăo de serviço ou locação. Dentre os mais comuns estäo os celebrados para prestação de assistencia técnica, fornecimento de mão de obra ou material, exploração de patente etc.

Em seu art. 40 (Seção 8 da Parte IT), o Acordo TRIPS regulamenta o controle das práticas de concorrencia desleal em licenças voluntárias. 0 paragrafo I do referido artigo trata do reconhecimento dos Estados-Partes de que:

algumas práticas ou condiçoes de licenciamento, relativas a direitos de propriedade intelectual, que restringem a concorrencia, podem afetar adversamente o comércio e impedir a transferéncia de tecnologia.

Pelo disposto no parágrafo 2, não há qualquer impedimento para que os Membros especifiquem, en suas respectivas legislaçöes, condiçoes e práticas para o licenciamento, adotando, inclusive, medidas de controle quanto à concortência desleal.

\subsection{Proteção de informaçāo confidencial}

A informaçáo não divulgada ou confidencial é regulada pelo art.39 do Acordo TRIPS. No parảgralo 1 desse artigo, assegura-se a proteção efetiva contra a concorrencia desleal, seguindo disposições do art.10 bis da Convenção de Paris (1967).

O parágralo 2 do Art. 39 vem estabelecer que pessoas físicas e juridicas terão a possibilidade de evitar que informacoes legalmente sob seu 
controle sejam divulgadas, adquiridas ou usadas por terceiros, sem seu consentimento, de maneira contrária a práticas comerciais honestas, desde que:

a) seja secreta, no sentido de que nāo seja conhecida em geral nem facilmente acessivel a pessoas de círculos que normalmente lidam com o tipo de informação em questão, seja como um todo, seja na configuração e montagem específicas de seus componentes;

b) tenha valor comercial por ser secreta; e

c) tenha sido objeto de precauções razoáveis, nas circunstâncias, pela pessoa legalmente em controle da informação, para mantê-la secreta (art 39.2, "a" e "b")

A expressão informação, contida no Acordo TRIPS, há que ser entendida como informação de qualquer natureza e que tenha valor comercial, podendo ser técnica, comercial ou industrial.

Para concessāo da proteção, a informação deverá atender aos seguintes requisitos: $a$ ser secreta e desconhecida; b) ter valor comercial; c) ter gozado de proteção através medidas razoáveis adotadas para tal fim e solicitadas por quem tenha, legalmente, seu respectivo controle.

Reza aquele Acordo, ainda, que os Estados-Partes, quando da adaptaço de suas regras de direito interno, devem procurar manter o equilbrio entre os interesses daquele que possui legalmente a informaçáo secreta e os interesses da sociedade de conhecer a tecnologia näo divulgada. Interpretacoes rigorosas ou complacentes devem ser descartadas.

\section{Os direitos hibridos}

Atualmente, constatamos a existência de dois lenômenos de real importância no campo da propriedade intelectual:

a) a utilizacáo do direto autoral, nas chamadas industrias culturais, primordialmente como meio de proteçao ao investimento e näo da criatividade estetica ou cientifica; e 
b) o do surgimento de novos objetos de proteçâ, alvo de novas modalidades de direito, ditas 'proteçoes hibridas', nem patentes, nem direitos autorais, como o software (proteça pelo copyright ou droit d'auteur modificados) ou as topografias de semicondutores (por um regime especifico $)^{21}$.

Considerando-se as fases da evolução humana, é possivel identificar o desalio imposto para a ciência do direito no regramento de condutas ante a velocidade das transformaçoes tecnologicas e sociais. A atual era da infomática e o surgimento dos computadores pessoais, Intemet, as redes on line, www e seu uso cada vez mais crescente, faz com que os órgãos jurisdicionais venham se defrontar com situaçōes antes inimagináveis, e que pareciam estar melhor alocadas no campo da ficção.

O surgimento dessa nova cultura leva à indagação acerca da sobrevivencia do direito autoral ante os seguintes desafios:

a) a lacilidade com que poderão ser produzidas e distribuidas cópias não autorizadas;

b) a ocorrência de execução pública de obras devidamente protegidas, sem prévia e necessária autorização dos seus titulares;

c) o surgimento de obras derivadas (obras originais digitalizadas);

d) que textos e imagens disponibilizados por serviços on line sejam passíveis de apropriação indevida ${ }^{22}$.

Tais obstaculos deixam de existir a partir do momento em que sejam solicitadas, previamente, licenças para os titulares desses direitos. Mas, na prática, o processo de autorização é extremamente moroso, envolvendo gastos com serviços especializados e pagamento de royalties, criando uma situaç̃o propicia à violação dos direitos autorais. Nesse contexto, verifica-se a necessidade da proteçăo de tecnologias autoduplicativas, como é o caso do

\footnotetext{
21 imunabiconb:

22 GANDELMAN, Hentique. De Gutenberg a Internet - Direitos Autorais na era digital. 2, ed., Editora Record, 1997, p. 358.
} 
software, produtos de biotecnologia, onde a reprodução desprende-se de uma operação intelectual, tornando-se apenas uma operação objetiva.

No campo internacional, o GATT trouxe significativo avanço sobre a questăo ao considerar a propriedade intelectual (p. ex. um software) como um produto, e năo um serviço, passivel de apropriação. Considerando-se a propriedade um bem economico, deve fluir no mundo em conformidade com os parâmetros legais, para não prejudicar as economias, quer sejam fortes ou fracas.

\section{O Acordo TRIP'S no Brasil}

Com vigencia em nosso pais a partir da promulgação pelo Decreto ${ }^{\circ}$ 1.355, de 31 de dezembro de 1994 (Diário Oficial da União, de 31/12/94). Em sua constituiçăo encontram-se os seguintes textos:

Parte I - Disposiçoes Gerais e Princípios Básicos;

Parte 11 - Padróes Relativos à Existência, Abrangência, e Exercício de Direitos de Propriedade Intelectual;

Parte 111 - Aplicação de Normas de Proteção dos Direitos de Propriedade Intelectual;

Parte IV - Obtenção e Manutenção de Direitos de Propriedade Intelectual e Procedimentos "inter Partes" Conexos:

Parte V - Prevenção e Solução de Controvérsias;

Parte VI - Arranjos Transitórios;

Parte VII - Arranjos Institucionais: Disposições Finais.

Em que pese a promulgaça do Decreto legislativo n." 30 de 15/12/94 e promulgado pelo Decreto n. 1.355 , de 31/12/94, as seguintes disposicoes do Acordo não se encontram em vigor no país, por força das disposiçōes transitórias do mesmo: art. 65 , parágrafo $4^{\circ}$ - Na medida em que um país em desenvolvimento Membro esteja obrigado peto presente Acordo a estender protecáo 
patentaria de produtos e setores tecnologicos que não se protegia em seu território na dala geral de aplicaçao do presente Acordo, conforme estabelecido no parägrafo $2^{\circ}$, ele poderá adiar a aplicaça das disposiçoes sobre patentes de produtos da Seçăo 5 da Parte II para tais setores tecnológicos por um prazo adicional de cinco anos.

No que diz respeito ao Brasil, além dos quatro tratados sobre propriedade industrial em vigor, temos a sua participação em dois acordos bilaterais (Panamá-Brasil e Uruguai-Brasil); Convenção Interamericana de 1911 - Buenos Aires - sobre Patentes de Desenhos e Modelos Industriais; Convenção Interamericana de 1923 - Santiago do Chile - sobre Marcas e Nomes Industriais.

Pode-se afirmar que é no campo da Propriedade Intelectual, mais precisamente da Propriedade Industrial, que se verifica uma maior interferencia no direito nacional com relação à aplicação direta de normas internacionais.

De sorte que, por intermédio dos depósitos internacionais (por exemplo: aplicação extraterritorial de marcas) fatalmente ocorrerá conflito entre as normas internas e as internacionais, fenòmeno este, tendente a se repetir de forma constante. A partir de então, faz-se necessária a revisão dos temos: internalização, interpretação, integração e destinação das normas internacionais.

A medida é necessária em razão das mudanças oriundas do fenômeno da globalização, ora em curso. E como tal, exige reflexäo, adaptação e interpretação dos conceitos tradicionais, ajustando-os, se necessário for, de maneira a permitir o efetivo engajamento dos vários setores nos processos de integração, pois a complexidade es rumos do mundo em que vivemos toma inadiavel a compreensão das reais dimensões destes impactos sobre paises, regiöes, continentes, populaçoes mais jrágeis ${ }^{23}$.

Ademais é preciso ter em conta que, nos dias atuais, a propriedade intelectual deixou de ser uma questão restrita apenas ao direito privado dos

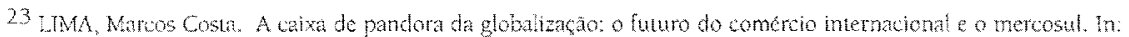
LIMA, MARCOS COSTA; MEDLIROS, MARCLL DE ALMELDA. (OF). O Mercosul no limat do sEculo XXI. Buenos Aires: ClACSO, 2000 , p.93.
} 
nacionais dos Estados, para também, ser um assunto que interessa ao direito público, principalmente em termos de relaçöes internacionais, face as tendências de liberalização do comércio mundial.

No Brasil existem inúmeros tratados, acordos e convençóes sobre propriedade industrial, dentre os quais o Acordo sobre os Aspectos da Propriedade Intelectual relativas ao Comércio (TRIPs) - no âmbito da Organização Mundial do Comércio. Há que se mencionar ainda a Convenção da União de Berna de 1886, para a proteçăo do Direito Autoral.

O Acordo TRIP'S - Agreement on Trade-Related Aspects of Intellectual Property Rights é resultado de um longo processo de discussão no ámbito do GATT. Apesar de ser considerado como conjunto de regras mínimas de proteção, O TRIPs vem repetir principios de real importância como o do Tratamento Nacional e da Nação mais Favorecida ínsitos ao GATT.

Nessa esteira, o IRIP'S vem proibir tratamento diferenciado entre os participantes do acordo deixando também de estabelecer desigualdade entre nacionais e estrangeiros.

\section{A concorrência desleal}

A preocupação em estabelecer meios de proteçāo em relaçăo aos atos atentatórios contra marcas, patentes e propriedade intelectual, fez nascer no seio da Convenção de Paris (1883) a definição de concorrencia desleal. Em seu artigo $1^{\circ}$, dispõe que:

Constitui alo de concorrência desleal todo o ato de concorrencia contráno as práticas honestas em matéria industrial ou comercial.

Partindo-se da premissa de que a concorrência desleal constitui uma conduta inadequada do empresario no sistema de competiçá, que fere os principios da boa-fé e de naemene laedere, a concorrência efetiva constitui um ataque ao próprio regime de livre concorrencia, afetando, desse modo, a 'ordem pública econòmica'. A 'ordem pública economica' é o conjunto de normas básicas estruturantes do ordenamento juridico sobre a produção e a circulaça de riqueza em uma sociedade ${ }^{2.4}$, temos então que, práticas suscetiveis de criar confusão com os produtos de um determinado concorrente, seja com alegaçoes falsas 
no sentido de fazer desacreditar o mesmo, săo atos vedados no exercício do comércio.

$O$ direito de concorrencia objetiva a proteção da liberdade de concorrência em seu sentido amplo. Abrangendo ainda, esse conceito duas espécies: a proteção contra a concorrencia desleal e a proteção da concorrencia efetiva, dado o principio informador comum a ambos, bem cono o interesse público na tutela da live concorrencia.

Nesse sentido, vejamos a decisão jurisprudencial do Supremo Tribunal Federal:

CONCORRENCIA COMO LIBERDADE. A Tive concorrencia, como toda liherdade, não é irrestrita, o seu direito encontra limites nos preceitos dos outros concorrentes pressupondo um exercicio legal e honesto do direito proprio, expresso da probidade profissional. Excedidos esses limites surge a concorrência desleal.

Procura-se no àmbito da concorencia desleal os atos de concorrencia fradulenta ou desonesta, que atentam contra o que se tem como correto ou normal no mundo dos negocios, ainda que näo infrinjam diretamente patentes ou SINAIS DISTINTIVOS REGISTRADOS. (RTJ. 56/453-5)

No contexto atual, a velocidade da informaçào constitui-se em um poderoso instrumento no processo de globalizaçăo, năo apenas em termos de comércio internacional atrelado à busca incessante e eficaz de tecnologias, que objetiva incrementar as trocas de mercadorias entre os paises; mas também, en termos de proteção da produção intelectual.

Tanto assim que, se fez necessária a sua inclusão no GATT em razão do liacasso das medidas unilaterais e do bilateralismo impostos pelos paises da União Européia e Estados Unidos. Acresce a esse fato, o descontentamento dos países ricos ante à lentidão de se conseguir a efetividade das medidas de protecão da propriedade intelectual no ámbito da OMPI, pois, conciliar os interesses dos países desenvolvidos com os em desenvolvimento, é tarela árdua, posto que cada qual - ocupando posiçoes distintas entre si - tem objetivos e necessidades diferentes.

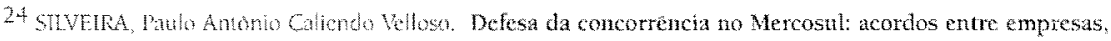
abuso de posica dominante e concentraçes, Sito Pato. Lir, $2998,0,33$. 


\section{A propriedade intelectual no MERCOSUL}

No contexto do Mercosul, a partir da Decisão CMC $9 / 95$ teve inicio às primeiras negociaçöes para a elaboração de acordos - a partir das normas internacionais vigentes na matéria - que protegessem adequadamente os direitos de propriedade intelectual no Mercosul.

Assim, foi criado em 1995 o Protocolo de Harmonização de Normas sobre Propriedade Intelectual no Mercosul, em Matérias de Marcas, Indicaçoes de Procedência e Denominaçôes de Origem, como forma de evitar práticas desleais e eventuais obstáculos ao comércio, uma vez que cada pais possui uma estrutura própria para cuidar da aplicação da legislação de propriedade intelectual.

Na Argentina, encontramos: Leis sobre Patentes $n^{\circ} 24.481 / 95$ e 24.572/95, ambas regulamentadas pelo Decreto $n^{\circ} 260 / 96$. Esta regulamentaça substituiu a antiga Lei 111 , de $11 / 10 / 1864$. Não existe legislação especifica sobre modelo de utilidade, mas sobre modelos e desenhos industriais, existe o Decreto-lei 6.673 de 9.8.63, ratificado pela Lei 16478.

A Lei 22.362 de 26.12.81, dispöe sobre Marcas, Denominaçoes Comerciais e Referência às Indicaçoes Geográficas. As denominaçōes de origem não se encontram legisladas, a única menção feita à elas, se encontra na lei de marcas, a qual em seu artigo $3^{\circ}, c$, próbe o registro das denominaçoes de origem como marca.

O Protocolo de Harmonização de Normas sobre Propriedade Intelectual. no Mercosul, em Matérias de Marcas, Indicações de Procedência e Denominaçóes de Origem, está em trâmite administrativo, pendente ainda de aprovação legislativa.

No Brasil entrou em vigor em 15.5.97, a Lei 9.279, de 1/05/96, dispondo sobre invençōes, modelos de utilidade, desenhos industriais, marcas, indicaçōes geográficas e concorténcia desleal. A Lei 9.279 substituiu a Lei $5.772 / 7$ ].

A tramitação do Protocolo no Congresso Nacional está suspensa, sendo o texto retirado pela Mensagem $n^{\circ} 1.872$, de 9/12/99. 
No Paraguai, sobre patentes de invençäo, encontra-se em vigor a Lei 773, de 03/10/95. Há que se observar que àquela época havia projeto de lei visando sua modificação. Os Modelos e Desenhos industriais estão regulados na Lei 868, de 02/1/81, enquanto que as Marcas e as designaçóes comerciais, segundo a Lei 751 , de $20 / 10 / 79$, essencialmente modilicada pela Lei 1258 , de 13/10/87.

O Protocolo de Harmonização de Normas sobre Propriedade Intelectual no Mercosul, em Materias de Marcas, Indicaçôes de Procedència e Denominaçōes de Origem foi aprovado pela Lei $n^{\circ} 912$, de 01/08/96, e o instrumento de ratificação foi depositado em $15 / 11 / 96$.

No Uruguai, as patentes de invenção säo reguladas pela Lei 10089, de $12 / 12 / 41$, regulamentada por um Decreto de 04/09/42. Os modelos de utilidade e modelos ou desenhos industriais se encontram no Decreto-lei 14.549 , de $29 / 07 / 76$.

Já a Lei 9.956 , de 04/10/40, com seu decreto regulamentar de $29 / 11 / 40$, tratam das marcas de fábrica. Convém ressaltar que o Uruguai desde 1967, possuía um Decreto específico tratando das marcas de serviço, é o Decreto 6.499/67, de 28/09/67.

O Protocolo foi incorporado no ordenamento interno pela Lei 17.052 , de 14/12/98, publicada no Diário Oficial de 08/01/99, cujo instrumento de ratilicaçao está ora em fase de depósito.

Apesar do Tratado de Assunção visar uma prolunda harmonização em todas as áreas da propriedade intelectual, o Protocolo de Harmonizaça de Normas sobre Propriedade Intelectual no Mercosul, em Matérias de Marcas, Indicações de Procedência e Denominações de Origem - em razão da adoção da mesma técnica legislativa do Convênio de Paris que, por sua vez, serviu de modelo para o Acordo TRIPS da OMC - tinha por objetivo regular os termos que poderiam obstaculizar a livre circulaçăo de bens e serviços, ressalvando as particularidades das legislações internas. 


\section{Conclusões}

A conclusão que se chega é que o Protocolo de Harmonização de Normas sobre Propriedade Intelectual no Mercosul, em Matérias de Marcas, Indicaçōes de Procedência e Denominaçôes de Origem nāo buscou a criação de um registro centralizado de marcas em defesa de tais direitos, tampouco não buscou harmonizar as questōes nacionais relativas ao tema e, que certamente trarão futuros problemas, como a colidência de marcas, as importaçoes paralelas, entre outros.

O Protocolo apresenta uma grande parte de disposiçoes considerada como standards mínimos e uma série de disposições a serem cumpridas pelos Estados, o que o torna semelhante, neste aspecto, às Convenções internacionais sobre o assunto.

Atualmente, o estudo da propriedade intelectual tem por base não só a legislação civil - direitos reais - como a legislação comercial através do Código de Proteção da Propriedade Industrial. Assim, pode-se alirmar que a junção desses dois ramos do direito no que pertine à propriedade intelectual, faz nascer um novo ordenamento onde tal patrimônio adquire contornos próprios de um direito de cunho internacional, de caráter eminentemente híbrido.

Nesse sentido, verifica-se a necessidade de proteção de tecnologias autoduplicativas como é o caso do software, produtos de biotecnologia, onde a reprodução desprende-se de uma operação intelectual, tornando-se apenas uma operação objetiva. Assim sendo, a preocupação com a proteção dada à tecnologia, ao conhecimento apesar dos compromissos assumidos anteriormente, parece diluir-se por completo.

No tocante ao Mercosul, onde os países almejam não a simples troca internacional de mercadorias, mas uma efetiva e eficaz integração, objetivando a criação de um Mercado Comum, torna-se imperioso o aprofundamento das discussões sobre o tema em questão. 


\section{BIBLIOGRAFIA}

BARBOSA, DENIS BORGES. [online] Disponivel na Intemet via: http//wwwnbb.combr/practice/intel html

BARROSO, HELENA ARANDA; TESHMA, MARCIA. Consideraçoes sobre a propriedade intelectual no änbito do Mercosul. In: ENCUENTRO 1NTERNACIONAL DE DERECHO DE AMERICA DEL SUR, 9., 2000, La Paz, Bolívia.. Anais... Bolivia, 2000, p.695-699.

BAS50, MARISTELA. O direito internacional da propriedade intelectual. Porto Alegre: Livmaria do Acvogado, 2000.

BLASI, GABRIEL DI, GARCIA MARIO S, MENDES, PAULO PM. A Propriedade Industrial - O sistema de Marcas, Patentes e Desenhos Industriais amalisados a partir da Lei n. 9.279 , de 14 de maio de 1996. Rio de Janeiro: Forense, 2000.

GANDELMAN, HENRIQUE De Gutenberg à Internet - Direitos Autotais na era digital, 2. ed., Rio de Janeiro: Edilora Recom, 1997.

LIMA, MALCos COSTA. A caixa de pandora da globalizacão: o huro do comércio internacional e o mercosul. In: IIMA, MARCOS COSTA; MEDEIROS, MARCELO DE ALMEIDA. (org). O Mercosul no limiar do seculo XXI. Sāo Paulb:Cortez; [Buenos Aires; Argentina]: CLACSO, 2000

MORO, MATEe CECLLA FABBR, A propriedade industrial no mercosul. In: BASTOS, CELSO RIBEIRO; CAUDIO FNNKEISTEIN. São Eato: Instituto Brasileito de Direto Constitucional, 1998.

OKEEF THOMAS ANDREW LOS probables temas de conflicto entre el mercosur y los ectu en las negociaciones para crear una área de lbre conercio de las américas. In: PIMENTEL, LUZ OTÁvIO (org) Mercosul no Cenáno Internacional: Direito e Sociedade. Vol.1, Curitiba Jumá Editora, 1998. PIMENTEL, LULZ OTAVIO. Processo de mundialização e produção das normas jurídicas para o comércio: o caso da propriedade industrial. Revista Jurídica da Universidade Estadual de Ponta Grossa Ponta Grossa, ano I, v.2, p.257-285, jan./jun. 1998.

Direito Industrial - As funçoes do Direito de Patentes. Porto Alegre:

Sintese, 1999.

SILY, ROBERTO LULZ. Direito econômico internacional e direito comunitário. Belo Horizonte: Del key, 1995

SIVEIRA, MAULO ANTONIO CALLENDO VELLOSO. Defesa da concorrência no Mercosul acordos entre empresas, abuso de posiça dominante e concentraçôes. São Paulo: 1Ti, 1998.

SOARES, JOSE C. T. Lei de Patentes, Marcas e Direitos Conexos-Lei 9.279-14.05.1996. Săo Paulo: Editora Revista dos Tribmais, 1997.

TRIPS - Trade Related Aspectos of Intellectual Property Rights. Acordo Constitutivo da Organizaço Mundial do Comerco, 01/01/1995. 